\title{
Conceptualizing and Analyzing Business Ecosystem Service Offerings
}

\author{
Christian Betz \\ University of St. Gallen \\ christian.betz@student.unisg.ch
}

\author{
Reinhard Jung \\ University of St. Gallen \\ reinhard.jung@unisg.ch
}

\begin{abstract}
Business ecosystems are dynamic structures of various actors who co-create value. By combining complementary and substitute services, these actors create integrated offerings. This paper proposes a conceptual model which supports the analysis of ecosystems by decomposing the offering into distinct modules. Each module represents a beneficiary-provider duality with a specific value proposition and activities to be performed. It further describes, how different service modules contribute and may change the network-level purpose. The research follows design science and was facilitated in a consortium setup to integrate practitioners' insights. The paper contributes by developing design principles for a service configuration model, identifying relevant activities to describe service creation, providing a logic to configure distinct services into a whole, and introducing the concept of substitutes into the discussion.
\end{abstract}

\section{Introduction}

Technology companies such as Apple, Facebook, Amazon or Chinese giants such as Tencent and Alibaba, are just a few examples of companies who were able to leverage the potential of network structures such as business ecosystems [1], [2]. These companies leverage modern information and communication technology to create innovative and more complex services by collaborating with partner companies [3]-[5]. Collaboration is enabled by advanced technology-driven collaboration mechanisms such as real-time coordination [6] promoting the formation and development of business ecosystems. Success tends to come to those organizations, who embrace and manage these interdependencies, bringing together different entities [7]. Therefore, interest in this topic has been growing steadily among researchers and practitioners [1]. The management consultancy McKinsey \& Company, for example, estimates that by 2025 approximately $\$ 60$ trillion in revenues of global production will be created in business ecosystems [8]. Network structures, in which companies collaborate toward a shared goal, such as supplier and distributor networks managed by automobile companies, have been around for quite a long time, however, "[...] what's changed is that most of today's fastest growing companies, from Amazon and Google, to Alibaba and Tencent, to Uber and WeWork - are explicitly positioning themselves as ecosystem players [...]" [9]. Many of these companies cultivated capabilities to orchestrate resources of others [1], [10], which are provided by autonomous parties, ultimately leading to offerings that are greater than the sum of its parts [11].

Jacobides et al. understand the formation of business ecosystems as a result from complementary products or services, which increase their value in production or use [1]. This creates multilateral dependencies among the parties in business ecosystems [1], [5]. While the premises of complementary services [1], [6] and their orchestration [10], [12] have been discussed from various perspectives, it remains difficult to analyze the interdependency of single services. The authors address the problem of how a business ecosystem offering can be conceptualized and analyzed.

Against this backdrop, this paper aims to contribute to the academic discussion by developing a model for the analysis of services in business ecosystems, supporting both researchers and practitioners with an approach to decompose service offerings into single building blocks. Therefore, the paper tries to answer the following research questions: (A) What are relevant activities to describe complementary services in business ecosystems? (B) How can complementary services in business ecosystems be analyzed? To answer these questions, the subsequent paragraphs develop an artifact according to design science research (DSR). Section 2 provides the theoretical foundation. Section 3 elaborates on the methodology. Section 4 develops the artifact. Section 5 discusses the results. Section 6 concludes with the main findings, limitations, and research opportunities.

\section{Theoretical Foundation}

The term ecosystem dates back to the early 1990 s [13], [14] and may refer to differing concepts, such as business ecosystems [1], innovation ecosystems [15], platform ecosystems [1], [16], knowledge ecosystems [17], and service ecosystems [18]. The business ecosys- 
tem stream focuses on the network of relationships between various actors and on the configuration of activities [5]. The stream of innovation ecosystems puts the analytical focus on (technological) innovations and describes, how interdependencies between different actors can be identified and how they may be resolved when implementing innovative solutions [19], [20]. The platform ecosystem stream focuses on the transactional infrastructure, technical interfaces and underlying value creation architecture [21], [22]. Knowledge ecosystems put the analytical lens on the creation and exchange of knowledge throughout a network [17], [23]. Service ecosystems refer to a temporal structure of loosely coupled actors who co-create value in a dynamic system [24]. The authors position this article in the business ecosystems area (hereafter referred to as ecosystems).

Due to the broad use of the term ecosystems [2], it is often difficult to differentiate the concept from other, prevailing concepts (e.g. supply chains). The design of the artifact will be backed with the following seven conceptual cornerstones. (1) The authors assume that ecosystems form a structure of several actors that consists of collaborative relationships [23], subject to a continuous dynamic change [24]. (2) The authors assume that the ecosystem offering comprises components from different interdependent [25] actors across industries [26]. (3) The actors are assumed to act autonomously in a non-hierarchical organizational setup with their own individual goals [1], [5]. (4) Orchestration, meaning the coordination, influence, and direction of other firms is a necessary activity to enable the ecosystem to function [10]. (5) Each actor performs individual activities which materialize specific, complementary services [1], [5]. By leveraging the growing technological opportunities [25], complementary services can be coupled to form the overall ecosystem offering. This is strongly supported by the concept of modularity [27], [28]. The authors assume that specific activities form a distinct component, where complementary services can be coupled to form the overall ecosystem offering [1]. (6) Ecosystems form around a focal value proposition [5], which functions as reference for other actors to contribute resources or capabilities [29]. They address a shared purpose [30]. (7) Each actor is considered an active part of the value creation process by performing specific activities creating or consuming a service [31].

For the development of the proposed artifact, the authors used the above mentioned ideas to define the concept of ecosystems as follows: An ecosystems is a dynamic structure (1) of different interdependent (2) yet autonomous (3) actors, who coordinate (4) their complementary activities (5) towards a shared purpose (6) to co-create value (7).

This definition of ecosystems builds on the ideas of Jacobides et al. and Adner, who define ecosystems from a relationship and structural perspective [1], [5]. However, the definition was extended with additional aspects which support the development of the proposed model. It is important to distinguish the ecosystem concept from the platform concept, where a platform provides the foundation and technical infrastructure that supports the development of services and the exchange between multiple parties [22], [32].

For the remainder of this paper, there are two terms, which require further clarification: service and complementarity. The term service has been used in the context of ecosystems with various connotations. In this paper, the authors will use the term for both for physical goods and services. A good or service is the result of the configuration of activities performed by a company [33]. The term good addresses physical products and the term service addresses the intangible nature of products [34], where the latter describes a relationship of interactions between customers and service providers (company employees) [35]. Physical goods and services can be both considered as means to transfer knowledge and skills to the customer [36]. A good therefore provides an indirect service to the user [36], while he is considered a value co-creator. Hence, this paper uses the term service for both physical goods and immaterial services.

Complementarity is used to describe different assets that, when combined, increase each other's value. The concept can be leveraged to analyze multilateral interdependence of services in the ecosystem [5], while different types of complementarity [37] influence the structure of ecosystems [1]. The term may be used to describe input or output factors which increase their value when coupled, however, the authors consider complementarity "[...] as a relation among groups of activities." [38, p. 514], which increase marginal return of other activities when combined. This concurs with the activity approach in the later proposed artifact.

\section{Research Methodology}

\subsection{Design Science Research}

This paper develops a model to support researchers and practitioners to describe and analyze complementary services in ecosystems. It supports the understanding of how these distinct services are interconnected. A model can be understood as "[...] a set of propositions or statements expressing relationships [...]" [39, p. 256]. It must be designed flexible enough to ensure a broad applicability, but robust enough to generate general insights in different contexts. The model will be designed that researchers and practitioners can conceptualize offerings [40], [41]. 
To help address the problem of a lack of conceptual guidance and to support researchers and practitioners conceptualizing and analyzing an ecosystem offering, the authors chose the design science research (DSR) approach as the underlying research method [42], [43]. DSR focuses on creating innovative ideas or practices to solve problems, for which practitioners are the major information source with relevant experience and formal knowledge in the specific area [43], [44]. To connect academic insights with practical knowledge, the consortium research approach is applied [45].

In this setup, the researchers are working together with 41 representatives from 16 financial services companies located in Austria, Germany, and Switzerland. The practitioners and researchers come together on a regular basis to discuss the results, to exchange ideas and to further advance the jointly developed solutions. The research problem at hand was part of the continuous consortium research and has been addressed as follows.

Three physical workshop meetings took place between May 2019 and May 2020. During each of these physical workshops, the intermediary results were presented to the company representatives in 90-minute presentations with additional time for questions. Afterwards, the group was split into three separate sub-groups to further discuss and refine the results. The feedback has been gathered and used to develop the model further after the physical meetings. During the time between the workshops, a virtual working group was established. The virtual working group consisted of 10 company representatives from 8 companies (a subset from the representatives of the physical workshops). The virtual meetings were conducted once between each of the physical workshops via Skype Call. Additionally, three individual phone interviews took place with selected parties to facilitate the requirement analysis.

For the development of the model, the researchers followed the three cycles of DSR proposed by Hevner [42]. During the relevance cycle, the initial need for the research artifact is validated and practical requirements are collected. This was addressed during physical workshops and in the telephone interviews. After the physical sessions with an initial input presentation about the topic, practical challenges in the area were discussed and initial requirements were collected. During the telephone interviews, individual challenges in the context of ecosystems were discussed and further requirements were identified. The rigor cycle integrates insights from academic sources. Desk research has been conducted to gather insights from the academic literature. The results have been shared during the physical meetings and in virtual meetings. During the design cycle, the artifact was developed iteratively. The fundamental task was to identify (a) the relevant components which such a model must have to meet the requirements and design principles and (b) what activity components best describe a single service in a way that also allows complementary modules to be linked together. The researchers started with a user need and a specific value proposition as basis. Following that, the researchers tried to identify relevant activity classes, which help to describe how the service is materialized. The researchers based their ideas on the concepts of the value chain [33], the value shop, and the value network [46]. Practical feedback and insights from the literature review were constantly integrated into the artifact design to guarantee practical relevance and academic rigor. This process was repeated until the artifact reached a sufficient maturity.

\subsection{Requirements and Design Principles}

The research activities started with the investigation of an initial demand for a model to conceptualize and analyze ecosystems. The practitioners validated the need for such a model. They acknowledged that tools are already available, helping to conceptualize service offerings i.e. value proposition design [47] or a method to identify or bundle services [34]. These tools, however, are only of limited help in the context of ecosystems. Adner proposed several tools (e.g. Innovation Risk Framework or the Value Blueprint) to address the ecosystem phenomenon, e.g. for the analysis of innovation interdependency or the configuration of offerings [20], however, they fall short to analyze specific services in detail. According to the identified need for a conceptual model, practical requirements have been developed. While different methods for requirement development have been proposed, the researchers applied a process similar to Meth or Proba [48], [49]. The requirements were developed in physical and virtual meetings, and in telephone interviews (table 1).

The theoretical requirements have been derived from a literature review, which aimed at identifying relevant components of the value-creation logic in ecosystems. EBSCO, ABI/INFORM, and Emerald have been selected as databases with the relevant academic literature in the areas of business information systems, organizational theory, and strategy. Additionally, back-ward and forward search has been facilitated. Selected papers from other research streams i.e. service design have been also taken into consideration. Eleven theoretical requirements have been developed (table 2).

Practical and theoretical requirements were consolidated into a list of 8 design principles (table 3 ), which served as guidelines when conceptualizing the functionalities. Intermediary results were validated with practitioners during the physical workshops and virtual group meetings. After the last workshop, the model was evaluated regarding its final maturity. 


\subsection{Evaluation of the artifact}

The results were discussed, and feedback was constantly gathered during the physical and virtual meetings. The model was applied in the second and third physical workshop, starting with a presentation of the model following a short case. The case comprised activities of buying real estate connected to mortgages and consumer loans (the case was selected to be close the practitioners' financial services experience). Specific activities were identified, and complementary service modules have been connected to construct an ecosystem service offering. The case study was discussed with the practitioners. After that, the practitioners were given an evaluation survey. The model was evaluated according to the structured approach proposed by Sonneberg \& vom Brocke [50], who provide key evaluation parameters according to the respective artifact type. As specified above, the artifact is considered a model according to March \& Smith [39], therefore, the following key evaluation parameters were selected: (a) completeness; (b) fidelity with real world phenomena; (c) internal consistency; (d) level of detail; and (e) robustness. The evaluation has been facilitated using a 5-point-Likert scale from 1 (strongly disagree) to 5 (strongly agree). For example, the questionnaire asked the following questions regarding completeness: "Is the model complete with regard to possible configuration dimensions?" The evaluation results are depicted in table 4.

\section{A model for conceptualizing service offer- ings in business ecosystems}

\subsection{Conceptualization of the model}

Based on the physical, virtual, and telephone meetings, practical requirements were collected. These requirements were consolidated to ensure similar aggregation levels. This process resulted in 14 requirements. They were discussed, pivoted, and evaluated with the practitioners during meetings until the practitioners were satisfied with the items (see table 1).

\begin{tabular}{|l|l|}
\hline \multicolumn{2}{|c|}{ Table 1. Practical requirements } \\
\hline No. & Description \\
\hline RP1 & $\begin{array}{l}\text { The model should include a user and a pro- } \\
\text { vider perspective when describing services }\end{array}$ \\
\hline RP2 & User needs must be included \\
\hline RP3 & $\begin{array}{l}\text { Different actors propose single specific } \\
\text { value propositions in the ecosystem }\end{array}$ \\
\hline RP4 & $\begin{array}{l}\text { The value proposition should be a central } \\
\text { point of reference when describing services } \\
\text { in the ecosystem }\end{array}$ \\
\hline
\end{tabular}

\begin{tabular}{|l|l|}
\hline RP5 & $\begin{array}{l}\text { The single value propositions add up to an } \\
\text { overall ecosystem value proposition }\end{array}$ \\
\hline RP6 & $\begin{array}{l}\text { Each service should be represented as a sin- } \\
\text { gle building block in the ecosystem }\end{array}$ \\
\hline RP7 & $\begin{array}{l}\text { A service building block is materialized by } \\
\text { performing specific activities by the actors }\end{array}$ \\
\hline RP8 & $\begin{array}{l}\text { Distinctive activities should describe how a } \\
\text { service is created, provided, or improved }\end{array}$ \\
\hline RP9 & $\begin{array}{l}\text { An activity should be considered that de- } \\
\text { scribes, how a good or service is used }\end{array}$ \\
\hline RP10 & $\begin{array}{l}\text { The activities must account for both physi- } \\
\text { cal goods and immaterial services }\end{array}$ \\
\hline RP11 & $\begin{array}{l}\text { A focal building block represents a refer- } \\
\text { ence point for complementary building } \\
\text { blocks }\end{array}$ \\
\hline RP12 & $\begin{array}{l}\text { Complementary service building blocks } \\
\text { contain activities, which provide value for } \\
\text { the reference service building block }\end{array}$ \\
\hline RP13 & The model should address substitutes \\
\hline RP14 & Each actor must benefit from participation \\
\hline
\end{tabular}

During the rigor cycle, requirements have been identified from the literature review. The requirements have been aggregated and are presented in table 2 .

\begin{tabular}{|c|c|c|}
\hline \multicolumn{3}{|c|}{ Table 2. Theoretical requirements } \\
\hline No. & Description & Ref. \\
\hline RT1 & $\begin{array}{l}\text { A shared purpose on the network } \\
\text { level describes how services and } \\
\text { technologies should evolve }\end{array}$ & $\begin{array}{l}{[10],} \\
{[30]}\end{array}$ \\
\hline RT2 & $\begin{array}{l}\text { A focal value proposition functions } \\
\text { as reference point for complemen- } \\
\text { tary value propositions }\end{array}$ & $\begin{array}{l}{[1],[5],} \\
{[6],[26]} \\
,[48]\end{array}$ \\
\hline RT3 & $\begin{array}{l}\text { Each party contributes a specific } \\
\text { value proposition }\end{array}$ & $\begin{array}{l}{[5],[23]} \\
,[25]\end{array}$ \\
\hline RT4 & $\begin{array}{l}\text { Single value proposition compo- } \\
\text { nents influence the overall compo- } \\
\text { sition of the ecosystem }\end{array}$ & $\begin{array}{l}{[14],} \\
{[26]}\end{array}$ \\
\hline RT5 & $\begin{array}{l}\text { Specific activities are performed to } \\
\text { materialize a value proposition }\end{array}$ & [5], [19] \\
\hline RT6 & $\begin{array}{l}\text { The activities must describe the } \\
\text { creation of physical goods and im- } \\
\text { material services }\end{array}$ & [5], [46] \\
\hline RT7 & $\begin{array}{l}\text { Complementary value propositions } \\
\text { consist of activity groups which } \\
\text { lead to synergies when paired }\end{array}$ & $\begin{array}{l}{[1],} \\
{[38],} \\
{[52]}\end{array}$ \\
\hline RT8 & $\begin{array}{l}\text { Substitute value propositions, } \\
\text { which consist of similar technolo- } \\
\text { gies (patterns of activities), en- } \\
\text { hance the network }\end{array}$ & $\begin{array}{l}{[53],} \\
{[54]}\end{array}$ \\
\hline RT9 & $\begin{array}{l}\text { The actors align their activities to } \\
\text { co-create and co-evolve the eco- } \\
\text { system offering }\end{array}$ & $\begin{array}{l}{[10],} \\
{[14],} \\
{[55]}\end{array}$ \\
\hline
\end{tabular}




\begin{tabular}{|c|c|c|}
\hline RT10 & $\begin{array}{l}\text { The user preferences must be in- } \\
\text { cluded into the analysis }\end{array}$ & [1], [54] \\
\hline RT11 & $\begin{array}{l}\text { The user is a value-co-creator and } \\
\text { the usage must be included }\end{array}$ & $\begin{array}{l}{[36],} \\
{[52]}\end{array}$ \\
\hline
\end{tabular}

The design principles are developed by aggregating practical and theoretical requirements, see table 3.

\begin{tabular}{|l|l|l|}
\hline \multicolumn{3}{|c|}{ Table 3. Consolidated design principles } \\
\hline No. & Description & $\begin{array}{l}\text { Init. } \\
\text { Requ. }\end{array}$ \\
\hline P1 & $\begin{array}{l}\text { There is a network level vision or } \\
\text { shared purpose that aligns all services }\end{array}$ & RP5 \\
RT1 \\
\hline P2 & $\begin{array}{l}\text { Distinctive services modules com- } \\
\text { prise the fundamental building blocks } \\
\text { of the model with a value proposition } \\
\text { at the center }\end{array}$ & $\begin{array}{l}\text { RP6 } \\
\text { RT4 }\end{array}$ \\
\hline P3 & $\begin{array}{l}\text { A service module includes both a user } \\
\text { need and a provider value proposition } \\
\text { that he proposes in the ecosystem }\end{array}$ & RP1 \\
& $\begin{array}{l}\text { RP2 } \\
\text { RP14 }\end{array}$ & RT10 \\
RT11
\end{tabular}

In total, 8 design principles $(\mathrm{P})$ for the artifact have been developed by consolidating the requirements from the practitioners and from the literature review. The design principles are considered as the overarching guidelines for the model. They were used to address the generic features of the model [48].

\subsection{Presentation of research artifact}

The model considers two levels of analysis. We distinguish between a network-level shared purpose and actor-level services (P1). This means that there is an overall vision which is addressed by combining distinct services, represented by service modules (P2) (figure 1). The distinction of the two levels is helpful since with additional services, the overall offering changes, which might at the same time change the overall purpose or vision. Furthermore, the services on the actor level comprise a user need and a proposed value proposition (P3). These two components represent the core of a service module. Further, we define a focal service module (P4), which acts as point of orientation for other modules. The value proposition and ultimately the service will be materialized by performing specific activities (P5). The authors combined several activities from the strategic management literature [46], in order to account for a complete picture that fits for both goods and immaterial services (P6). Complementary service modules comprise activities, which increase the value of the initial service module (P7), and substitute service modules comprise activities which are similar to other service modules (P8) (figure 2).

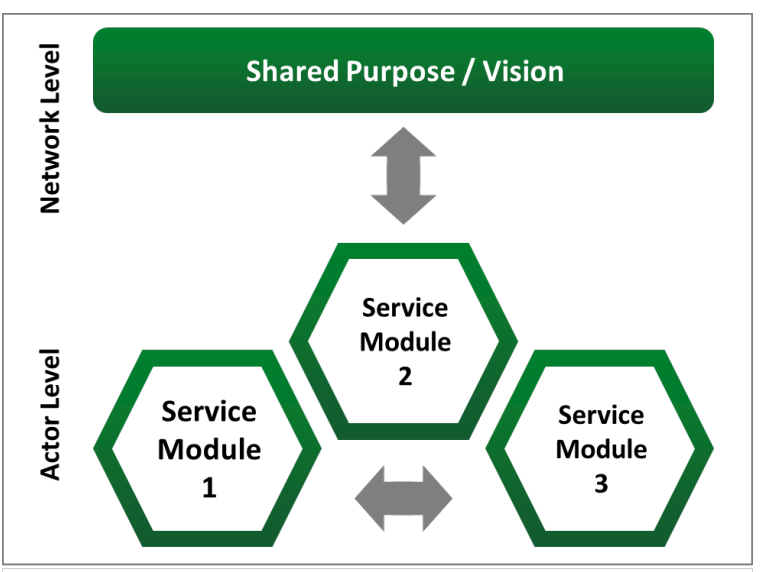

Figure 1: Levels of analysis

Six specific activities have been identified by combining ideas from the value chain [33] and the value shop [46]. The concept of value networks has also been considered [46], however, it has not been used for this model. First, the activities used in the proposed model require a finer granularity of detail for further analysis. The value network comprises all relevant production activities in the activity "service provisioning". Second, this paper only aims at describing activities for product manufacturing or service provisioning. Network promotion, contract management, or infrastructure operation are associated with orchestration in an ecosystem.

(1) Actor need: This component reflects the beneficiary's preference for the proposed service. Value is only created when a service is consumed (co-creation), therefore the user need must be considered.

(2) Value proposition: The value proposition acts as the interface between the activities and the customer 
need [56]. A company offers a product or service that will satisfy the need.

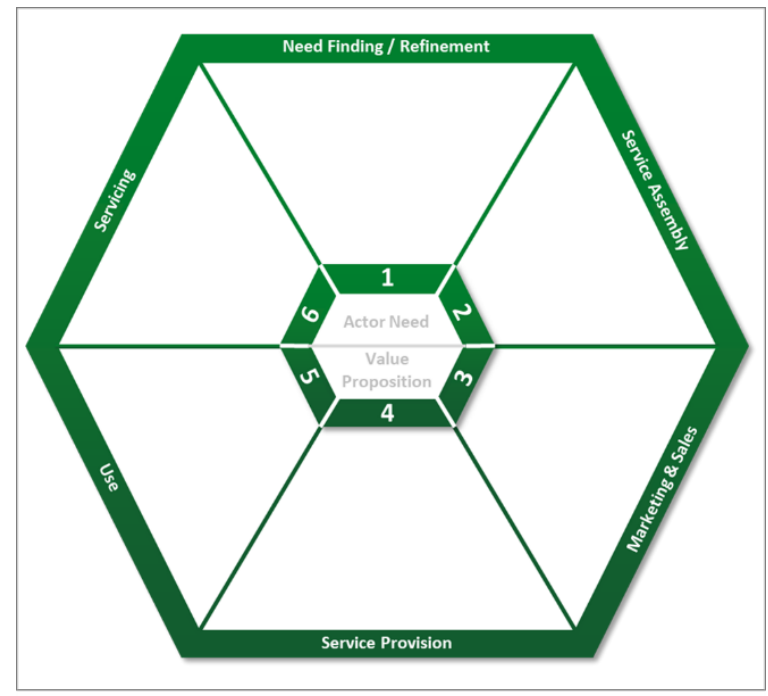

Figure 2: Service module

(3) Need finding / refinement: These activities intend to identify a beneficiary's preferences. It can be understood as the initial starting point where an organization tries to understand what the user wants and how this can be translated into a value proposition. A challenge arises, when perspectives of a company and of the user on the specific problem or need differ. This may be due to asymmetric information, where the company simply does not have the same information as the user and will define the problem differently. Furthermore, the problem or user need is subject to continuous change and evolves over time. Therefore, a continuous refinement is necessary.

(4) Service assembly: They describes how the service is created. This can refer to a physical product, which must be assembled. Therefore, the component can describe internal production processes including logistics. It can also refer to an intangible service. Therefore, it aggregates physical production and a service creation and hence offers more flexibility for analysis. The differentiation between service assembly and service provision also considers the possibilities of digitally enabled services, where time and place of creation and provision may be separate.

(5) Marketing \& sales: This aspect describes how the service is marketed. This includes how beneficiaries are approached, how the solution is communicated or advertised, and how payments are facilitated. These activities can also describe, how value-capture between different companies in the ecosystem is designed, where not each actor has an individual end-user interface since solutions are offered in complementary bundles rather than in single bits and pieces.
(6) Service provision: These activities describe how the service is delivered to the user. This can include a physical process, i.e. the customer receives a product or service at a specific location (e.g. delivery). It can also refer to a service that is provided through virtual interaction, i.e. a telephone call. It may also describe the provision of specific information. It is closely connected to solution assembly but considers that that manufacturing and delivery can be separated in terms of time and place.

(7) Use: These activities are performed by the beneficiary to consume or use the product or service, as value is created only when the beneficiary uses a service [36]. By integrating this into the model, the interaction with the user can be analyzed with more attention to how she can be supported in using or consuming it. This creates new possibilities to add complementary services, which can increase value.

(8) Servicing: Activities associated to this component describe how the value of the product may be maintained or revised by considering user feedback or complaints. It may refer to the provision and implementation of spare parts or repair activities as well as rework activities for the value proposition to hold. This corresponds to Porters "service activities" [33] and Stabell's "control and evaluation activities" [46]. This component, like the use component, integrates the beneficiary into the value creation process.

A service module is designed as duality between provider and beneficiary of a specific service. Both parties are considered as value co-creators. With this design, it is possible to configure an ecosystem offering with several modules that are interlinked, as depicted in figure 3. Service module 1, materialized through its activities, acts as a complementary module for the "use" activities from service module 2 , thereby increasing the value of all or at least the activities in the use category in module 2. Service module 3, 4, and 5 act as complementary to the "marketing \& sales" activities from module 2, however, modules 3,4 , and 5 are substitutes to each other as they comprise similar or equal activities. It is important to specify who is the beneficiary in the modules: module 1 is attached to the "use" activities of module 2, therefore, activities from module 1 support the usage of module 2. Modules 3, 4, and 5 are attached to the "marketing and sales" activities of module 2, therefore the beneficiary of module 3,4 , and 5 is located in module 2 .

\subsection{Evaluation of Research Artifact}

The artifact was iteratively developed and evaluated twice, which took place during the physical workshops. A structured approach was used in a survey according to Sonnenberg \& vom Brocke [50] with a Likert scale of 1: fully disagree to 5 : strongly agree (table 4). 
Table 4. Evaluation of artifact

\begin{tabular}{|l|l|l|}
\hline $\begin{array}{l}\text { Eval. crite- } \\
\text { ria }\end{array}$ & $\begin{array}{l}\text { Final } \\
\text { eval. }\end{array}$ & $\begin{array}{l}\text { Comments } \\
\text { (excerpt) }\end{array}$ \\
\hline $\begin{array}{l}\text { Complete- } \\
\text { ness }\end{array}$ & 4.03 & $\begin{array}{l}\text { Model could elaborate on or- } \\
\text { chestration activities (neces- } \\
\text { sary in the ecosystem) }\end{array}$ \\
\hline $\begin{array}{l}\text { Fidelity with } \\
\text { real world } \\
\text { phenomena }\end{array}$ & 3.69 & $\begin{array}{l}\text { Provides insights in theory, } \\
\text { but model needs to be chal- } \\
\text { lenged with more real cases }\end{array}$ \\
\hline $\begin{array}{l}\text { Internal con- } \\
\text { sistency }\end{array}$ & 4.03 & $\begin{array}{l}\text { Model could elaborate in } \\
\text { more detail on evolution of } \\
\text { the ecosystem, however, pro- } \\
\text { vides a clear snapshot }\end{array}$ \\
\hline $\begin{array}{l}\text { Level of } \\
\text { detail }\end{array}$ & 4.12 & $\begin{array}{l}\text { Level of detail is sufficient } \\
\text { for analysis in practice }\end{array}$ \\
\hline Robustness & 3.69 & $\begin{array}{l}\text { Different cases need to be an- } \\
\text { alyzed prove applicability of } \\
\text { the model }\end{array}$ \\
\hline & $\mathrm{n}=33$ & \\
\hline
\end{tabular}

The evaluation of completeness, internal consistency and the level of detail provides sufficient support from the practitioners. However, some aspects of orchestration within the ecosystem could be addressed in further design iterations. The model only provides a snapshot and does not fully address the time dimension. The evaluation of the criteria fidelity with real world phenomena and robustness tend to support the model, however, the practitioners request that the model is tested with more case examples.

\section{Discussion}

The model represents a tool to conceptualize and analyze service offerings in ecosystems. It distinguishes between a network-level and an actor-level and tries to decompose the offering into single modules. By design, each module represents a duality between a beneficiary and a provider in which a value proposition is the link between the user need and specific activities to be performed for the service to materialize. With this logic, the model provides service modules as a framework for further analyzing services in an ecosystem with a range of complementary products and services.

The concept of complementarity was discussed in the literature in sufficient detail, however, limited tools are available to conceptualize such constellations in detail. Furthermore, substitutes have not been addressed in the ecosystem context even though they seem to play an important role (i.e. different drivers with Uber, similar apartments with Airbnb, etc.). This distinction may be even more crucial when addressing orchestration activities, where complementary services may require coordination, but substitutes may require additional activities, i.e. providing access to and creating choice for such substitute services.

For an ecosystem to evolve, it is necessary to add complementary services. Initially, a focal service may be considered, such as a mobility or accommodation service. A mobility solution, e.g. offered by Uber, requires a taxi driver with his car, who is willing to pick up a user and drive him to his preferred location. A service for a digital payment solution is necessary and represents a complementary service for the Uber driver, so that she does not have to handle the cash. Each of these services

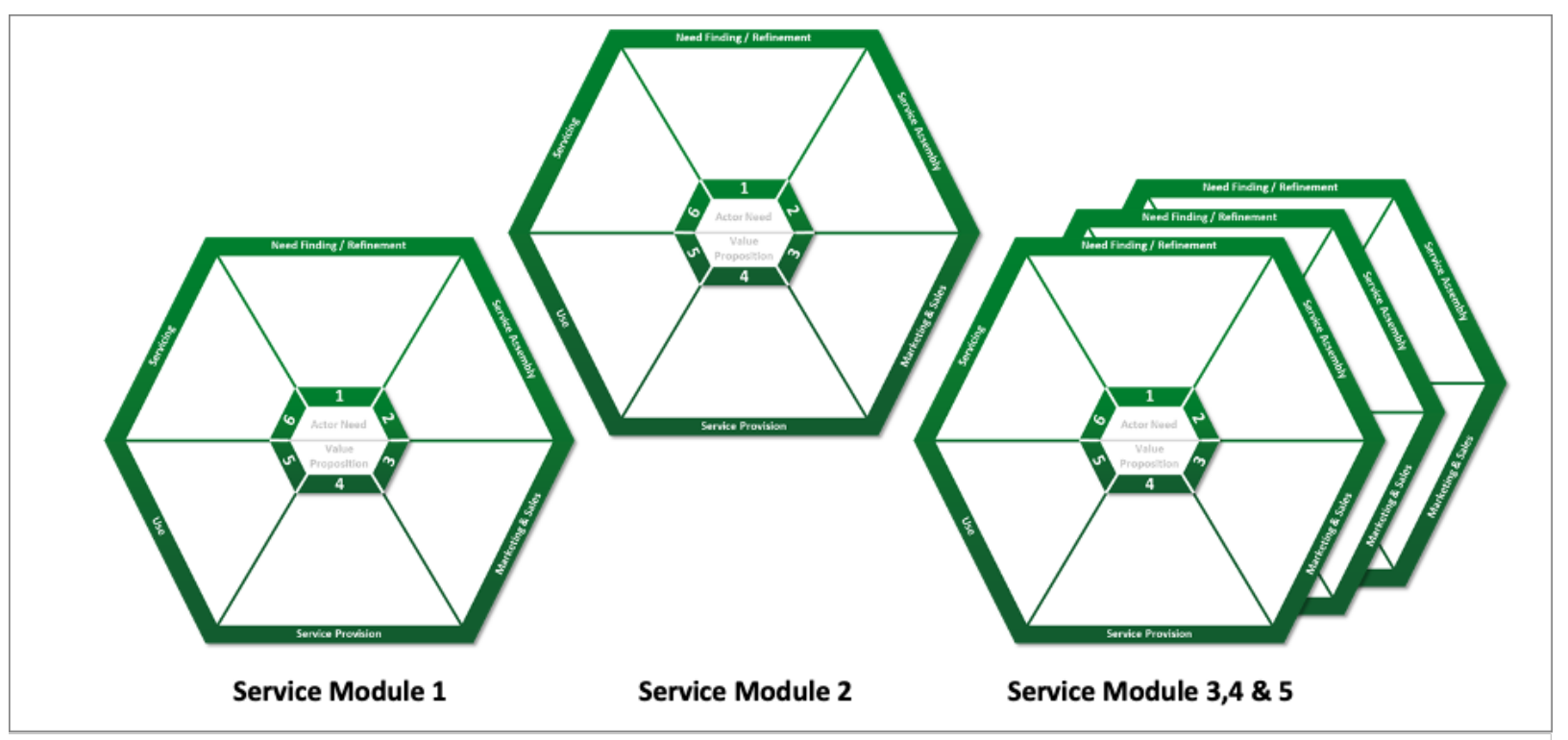

Figure 3: Complementary and substitute service modules in the ecosystem 
can be represented by a service module. While an ecosystem with only one provider (one driver) may not be feasible, the proposed model describes how substitutes come into play, namely several taxi drivers, who perform similar or equal activities.

There is a fine interplay between the network level shared purpose and the single services in the ecosystem, and one level may influence the other. The network level value proposition will reflect that, as observed in the Uber example. While Uber started by creating a network of taxi drivers, made available through a single click in the Uber App, the network moved to a much broader offering. Uber started with the vision "Tap a button, get a ride", representing a network of substitutable service modules (i.e. drivers). Over time, Uber differentiated the available services and added new complementary services (i.e. Uber X or Uber XL) and created a new, broader vision with its slogan "move the way you want". By now, Uber again added various new complementary services i.e. Uber eats or Uber fright and moved towards a new, even broader vision of "setting the world in motion" [57], orchestrating several service modules and their complements or substitutes.

The model tries to address all aspects which have been raised in the definition provided in section 2 . The model provides an approach to describe services in an ecosystem (1). The service modules are linked to each other, which represents interdependency (2), while each module is designed as a duality of a beneficiary and a distinct provider, addressing that distinct autonomous actors have been considered (3). Each service module constitutes different activities which are used to conceptualize and analyze the interplay of distinct modules which must be carefully coordinated so they can be linked together (4). These activities can be leveraged to better understand how modules are complementary to each other and how substitutes are integrated (5). We use a shared purpose on the network level as reference point to better understand the dynamic evolution of the ecosystem (6). Finally, the duality of the modules addresses two distinct actors and a service is only materialized when both perform activities, addressing the value co-creation requirement (7).

The model decomposes the service offering into digestible bits of activities. This provides two important advantages: firstly, the model provides transparency of how complementary and substitute services depend on each other, more specifically, which activities complement the service in what way. Secondly, with clearly identified activities, it is possible to identify new, additional modules which increase the value of the total offering. From an ecosystem management perspective, it therefore helps to understand the interdependencies of single services and it illustrates necessary orchestration implications (i.e. necessary exchange of information or the transfer of resources). This information, for example, may result in a specific design of a platform (i.e. the transactional infrastructure).

\section{Conclusion, Limitations, and Outlook}

This article addresses the research questions by (A) developing a model including distinct activities to describe ecosystems and (B) by providing a logic how these complementary and substitute services can be analyzed to understand how they are interconnected.

The paper contributes in four ways. First, design principles have been developed using the DSR approach. These principles could support other researchers in developing other artifacts, which support the conceptualization and analysis of ecosystems. Second, the paper develops a model that supports the configuration and analysis of services within ecosystems. In the model, each module is designed as a beneficiary-provider duality, integrating both parties in one module, that is distinct from other models which still describe ecosystem offerings from a single-company perspective. The modules can be flexibly linked. The model addresses the dynamic nature of ecosystems and uses two levels of analysis to provide transparency of the implications of changes on either level. Third, the model comprises 6 distinct activity categories with which single services in the ecosystem can be holistically described. These activities aggregate ideas from Porter and Stabell which this paper leverages to contribute to the ecosystem perspective and to co-value creation [33], [46]. Four, this article integrates the concept of substitutes into the discussion of ecosystems. This is a crucial element, that might imply distinct orchestration activities (i.e. Uber services, Airbnb apartments, etc.) compared to the coordination of complementary services, such as providing access to or supporting the user in choosing the appropriate service.

However, we identified possible limitations of this paper. So far, a general theory of ecosystems is missing [1], therefore, the design principles may be missing some important theoretical components. Furthermore, it may be difficult to find an appropriate granularity when choosing and describing complementary services. This has been specifically addressed by the practitioners during the artifact evaluation. Additionally, the shift in perspective towards a beneficiary-provider duality imposes a challenge for the practitioners which must be considered. A detailed method how to apply the model might be helpful. While the authors addressed orchestration activities, which are crucial when considering different complementary and substitute services, the model does not specify how exactly the services must be orchestrated. The model has been developed and evaluated to- 
gether with practitioners from the financial services industry. This may impose a bias regarding the general applicability for other industries. Additionally, this model only supports a snapshot of a business ecosystem. This must be considered when analyzing the activities, as the ecosystem is, per definition (section 2) subject to constant change. This dynamic development may require analyzing several points in time or using additional models to cope with the complex reality.

The authors see that there is a potential research gap regarding the orchestration activities in ecosystems. The model could provide a foundation upon which additional elements such as orchestration activities could be identified and further developed. This may be interesting, since ecosystems are sometimes considered to be more than just the sum of its parts, where orchestration may be the missing value creation component which fills this gap. The evolution of ecosystems is another interesting domain where a more detailed analysis of how additional services may influence the development of the whole network in one or the other direction. While this paper addressed business ecosystems specifically, it could be interesting to investigate, if the ideas also hold for domains, i.e. innovation or platform ecosystems.

\section{References}

[1] M. G. Jacobides, C. Cennamo, and A. Gawer, "Towards a Theory of Ecosystems," Strateg. Manag. J., vol. 39, no. 8, pp. 2255-2276, 2018, doi: 10.1002/smj.2904.

[2] J. Fuller, M. G. Jacobides, and M. Reeves, "The Myths and Realities of Business Ecosystems," MIT Sloan Manag. Rev., 2019.

[3] J. F. Moore, "Predators and Prey: A New Ecology of Competition," Harv. Bus. Rev., vol. 71, no. 3, pp. 75-86, 1993.

[4] M. Iansiti and R. Levien, "Strategy as Ecology," Harv. Bus. Rev., vol. 82, no. 3, pp. 1-11, 2004.

[5] R. Adner, "Ecosystem as Structure: An Actionable Construct for Strategy," J. Manage., vol. 43, no. 1, pp. 3958, 2017, doi: 10.1177/0149206316678451.

[6] C. Y. Baldwin, "Organization Design for Business Ecosystems,” J. Organ. Des., vol. 1, no. 1, pp. 20-23, 2012, doi: $10.7146 /$ jod.6334.

[7] T. Eisenmann, G. Parker, and M. W. Van Alstyne, "Strategies for Two-Sided Markets," Harv. Bus. Rev., vol. 84, no. 10, pp. 1-11, 2006, doi: 10.1007/s00199-006-0114-6. [8] R. Johnson, S. Moore, K. Petriwsky, C. Rice, C. John, and D. Sand, "Digital McKinsey: Insights of Winning in Digital Ecosystems," 0718 Hosp. Technol., vol. 3, no. 1, pp. 5-25, 2018.

[9] J. Birkinshaw, "Ecosystem Businesses Are Changing the Rules of Strategy," Harv. Bus. Rev., pp. 1-8, 2019.

[10] S. Nambisan and M. Sawhney, "Orchestration Processes in Network-Centric Innovation: Evidence From the Field," Acad. Manag. Exec., vol. 25, no. 3, pp. 40-57, 2011, doi: 10.5465/AMP.2011.63886529.

[11] M. Peltoniemi and E. Vuori, "Business Ecosystem as the new Approach to Complex Adaptive Business Environments," in Proceedings of EBusiness Research Forum, 2008, pp. 1-15.

[12] H. Lütjen, C. Schultz, F. Tietze, and F. Urmetzer, "Managing Ecosystems for Service Innovation: A Dynamic Capability View," J. Bus. Res., vol. 104, pp. 506-519, 2019, doi: 10.1016/j.jbusres.2019.06.001.

[13] M. L. Rothschild, Bionomics: Economy as Business Ecosystem. Beard Books, 1990.

[14] J. F. Moore, "Predators and Prey: A New Ecology of Competition," Harv. Bus. Rev., vol. 71, no. 3, pp. 75-86, 1993.

[15] R. Adner and R. Kapoor, "Value Creation in Innovation Ecosystems: How the Structure of Technological Interdependence Affects Firm Performance in New Technology Generations," Strateg. Manag. J., vol. 31, no. 3, pp. 306-333, 2010, doi: 10.1002/smj.821.

[16] G. Parker, M. van Alstyne, and X. Jiang, "Platform Ecosystems: How Developers Invert the Firm," MIS Q., vol. 41, no. 1, pp. 255-266, 2017, doi: 10.25300/MISQ/2017/41.1.13.

[17] K. Valkokari, "Business, Innovation, and Knowledge Ecosystems: How They Differ and How to Survive and Thrive within Them," Technol. Innov. Manag. Rev., vol. 5, no. 8, pp. 17-24, 2015, doi: 10.22215/timreview/919.

[18] R. F. Lusch and S. Nambisan, "Service Innovation: A Service-Dominant Logic Perspective," MIS Q. Manag. Inf. Syst., vol. 39, no. 1, pp. 155-175, 2015, doi:

10.25300/MISQ/2015/39.1.07.

[19] R. Adner and R. Kapoor, "Innovation Ecosystems and the Pace of Substitution: Re-Examining Technology SCurves," Strateg. Manag. J., vol. 37, no. 4, pp. 625-648, 2015, doi: 10.1002/smj.2363.

[20] R. Adner, The Wide Lens: What Successful Innovators See That Others Miss. New York, USA: Portfolio Penguin, 2013.

[21] A. Gawer and M. A. Cusumano, "How Companies Become Platform Leaders," MIT Sloan Management Review, vol. 49, no. 2, pp. 28-35, 2008.

[22] D. P. McIntyre and A. Srinivasan, "Networks, Platforms, and Strategy: Emerging Views and Next Steps," Strateg. Manag. J., vol. 38, no. 1, pp. 141-160, 2017, doi: 10.1002/smj.2596.

[23] B. Clarysse, M. Wright, J. Bruneel, and A. Mahajan, "Creating Value in Ecosystems: Crossing the Chasm Between Knowledge and business ecosystems.," Res. Policy, vol. 43, no. 7, pp. 1164-1176, Sep. 2014.

[24] S. L. Vargo and R. F. Lusch, "It's all B2B... and Beyond: Toward a Systems Perspective of the Market," Ind. Mark. Manag., vol. 40, no. 2, pp. 181-187, 2011, doi: 10.1016/j.indmarman.2010.06.026.

[25] M. Subramaniam, B. Iyer, and V. Venkatraman, "Competing in Digital Ecosystems," Bus. Horiz., vol. 62, no. 1, pp. 83-94, Jan. 2019, doi: 10.1016/j.bushor.2018.08.013. [26] P. Frow, J. R. McColl-Kennedy, T. Hilton, A. Davidson, A. Payne, and D. Brozovic, "Value Propositions: A Service Ecosystems Perspective," Mark. Theory, vol. 14, no. 3, pp. 327-351, Sep. 2014.

[27] C. Y. Baldwin and K. B. Clark, "Managing in an Age of Modularity," Havard Bus. Rev., no. 1997, 1997.

[28] C. Y. Baldwin and E. von Hippel, "Modeling a 
Paradigm Shift: From Producer Innovation to User and Open Collaborative Innovation," Organ. Sci., vol. 22, no. 6, pp. 1399-1417, 2011, doi: 10.2139/ssrn.1502864.

[29] E. Autio and L. D. W. Thomas, "Ecosystem Value CoCreation," Acad. Manag. Proc., vol. 2018, no. 1, pp. 1-30, 2018, doi: 10.5465/ambpp.2018.15913abstract.

[30] M. Burkhalter, Allocentric Business Models - An Allocentric Business Model Ontology for the Orchestration of Value Co-Creation Using the Example of Financial Service Ecosystems. St.Gallen, Switzerland: University of St.Gallen, 2020.

[31] E. Autio and L. D. W. Thomas, "Ecosystem Value CoCreation," in Academy of Management Annual Meeting Proceedings, 2018, no. April, pp. 1-30, doi: 10.5465/AMBPP.2018.15913abstract.

[32] A. Gawer and M. A. Cusumano, "Industry Platforms and Ecosystem Innovation.," J. Prod. Innov. Manag., vol. 31, no. 3, pp. 417-433, May 2014.

[33] M. Porter, Competitive Advantage: Creating And Sustaining Superior Performance. New York, USA: Free Press, 1985.

[34] T. Kohlborn, Identification and Evaluation of Service Bundles for Governmental One-Stop Portals. Brisbane, Australia: Queensland University of Technology, 2012. [35] C. Grönroos, Service Managing and Marketing. Managing the Moments of Truth in Service. Lexington, MA,USA: Lexington Books, 1990.

[36] S. L. Vargo and R. F. Lusch, "Evolving to a New Dominant Logic for Marketing," vol. 68, no. January, pp. 117, 2004, doi: 10.1509/jmkg.68.1.1.24036.

[37] D. J. Teece, "Profiting From Technological Innovation: Implications for Integration, Collaboration, Licensing and Public Policy," Res. Policy, vol. 15, no. 6, pp. 285-305, 1986, doi: 10.1016/0048-7333(86)90027-2.

[38] P. Milgrom and J. Roberts, "The Economics of Modern Manufacturing: Technology, Strategy, and Organization,"

The American Economic Review, vol. 80, no. 3. pp. 511-528, 1990.

[39] S. T. March and G. F. Smith, "Design and Natural Science Research on Information Technology," Decis. Support Syst., vol. 15, no. 4, pp. 251-266, 1995, doi: 10.1016/0167-9236(94)00041-2.

[40] J. vom Brocke, Referenzmodellierung. Gestaltung und Verteilung von Konstruktionsprozessen. Münster: Universität Münster, 2002.

[41] J. Becker, P. Delfmann, A. Dreiling, R. Knackstedt, and D. Kuropka, "Configurative Process Modeling. Outlining an Approach to Increased Business Process Model Usability," Inf. Resour. Manag. Assoc. Conf. (IRMA), New Orleans, 2004b, pp. 615-619, 2004.

[42] A. R. Hevner, "A Three Cycle View of Design Science Research,” Scand. J. Inf. Syst., vol. 19, no. 2, pp. 87-92, 2007.

[43] A. R. Hevner and S. T. March, "Design Science in
Information Systems Research," MIS Q., vol. 28, no. 1, pp. 75-105, 2004, doi: 10.2307/25148625.

[44] S. Gregor and D. Jones, "The Anotomy of a Design Theory," J. Assoc. Inf. Syst., vol. 8, no. 5, pp. 312-335, 2007. [45] H. Oesterle and B. Otto, "Consortium Research," Bus. Inf. Syst. Eng., vol. 2, no. 5, pp. 283-293, 2010, doi: 10.1007/s12599-010-0119-3.

[46] C. B. Stabell and Ø. D. Fjeldstad, "Configuring Value for Competitive Advantage: On Chains, Shops, and Networks," Strateg. Manag. J., vol. 19, no. 5, pp. 413-437, 1998, doi: 10.1002/(sici)1097-0266(199805)19:5<413::aidsmj946>3.3.co;2-3.

[47] Strategyizer, "Value Proposition Design," 2020.

[Online]. Available:

https://www.strategyzer.com/books/value-propositiondesign. [Accessed: 09-Jul-2020].

[48] H. Meth, B. Mueller, and A. Maedche, "Designing a Requirement Mining System,” J. Assoc. Inf. Syst., vol. 16, no. 9, pp. 799-837, 2015.

[49] D. Proba and R. Jung, "Defining Situational Characteristics for Situational Agile Method Engineering," 25th Am. Conf. Inf. Syst. AMCIS 2019, pp. 1-10, 2019.

[50] C. Sonnenberg and J. vom Brocke, "Evaluations in the Science of the Artificial - Reconsidering the Build-Evaluate Pattern in Design Science Research," Adv. Theory Pract. Proc. 7th DESRIST Conf. Las Vegas, NV, USA, vol. 7286, pp. 381-397, 2012, doi: 10.1007/978-3-642-29863-9.

[51] C. Betz, M. Burkhalter, and R. Jung, "Prerequisites for Value Co-Creation in Business Ecosystems," 25th Am. Conf. Inf. Syst. AMCIS 2019, pp. 1-5, 2019.

[52] E. Autio and L. D. W. Thomas, Innovation Ecosystems: Implications for Innovation Management, no. April 2020. 2014.

[53] D. Cetindamar, R. Phaal, and D. Probert, "Understanding technology management as a dynamic capability: A framework for technology management activities," Technovation, vol. 29, no. 4, pp. 237-246, 2009, doi: 10.1016/j.technovation.2008.10.004.

[54] E. den Hartigh and T. van Asseldonk, "Business Ecosystems: A Research Framework for Investigating the Relation Between Network sStructure, Firm Strategy, and the Pattern of Innovation Diffusion," in ECCON 2004 Annual Meeting, 2004, pp. 1-38.

[55] R. Parente, K. Rong, J. M. G. Geleilate, and E. Misati, "Adapting and Sustaining Operations in Weak Institutional Environments: A Business Ecosystem Assessment of a Chinese MNE in Central Africa," J. Int. Bus. Stud., vol. 50, no. 2, pp. 275-291, 2019, doi: 10.1057/s41267-018-0179-z. [56] A. Osterwalder, “The Business Model Ontology A Proposition In A Design Science Approach," pp. 285-287, 2004.

[57] Uber, “Uber Investor Relations," 2020. [Online]. Available: https://investor.uber.com/home/default.aspx. [Accessed: 20-Apr-2020]. 